\title{
Food and the relation between values and attitude characteristics
}

Citation for published version (APA):

Dreezens, E. A. A., Martijn, C., Tenbült, P., Kok, G. J., \& de Vries, N. K. (2005). Food and the relation between values and attitude characteristics. Appetite, 45(1), 40-46.

https://doi.org/10.1016/j.appet.2005.03.005

Document status and date:

Published: 01/01/2005

DOI:

10.1016/j.appet.2005.03.005

Document Version:

Publisher's PDF, also known as Version of record

Document license:

Taverne

Please check the document version of this publication:

- A submitted manuscript is the version of the article upon submission and before peer-review. There can be important differences between the submitted version and the official published version of record.

People interested in the research are advised to contact the author for the final version of the publication, or visit the DOI to the publisher's website.

- The final author version and the galley proof are versions of the publication after peer review.

- The final published version features the final layout of the paper including the volume, issue and page numbers.

Link to publication

\footnotetext{
General rights rights.

- You may freely distribute the URL identifying the publication in the public portal. please follow below link for the End User Agreement:

www.umlib.nl/taverne-license

Take down policy

If you believe that this document breaches copyright please contact us at:

repository@maastrichtuniversity.nl

providing details and we will investigate your claim.
}

Copyright and moral rights for the publications made accessible in the public portal are retained by the authors and/or other copyright owners and it is a condition of accessing publications that users recognise and abide by the legal requirements associated with these

- Users may download and print one copy of any publication from the public portal for the purpose of private study or research.

- You may not further distribute the material or use it for any profit-making activity or commercial gain

If the publication is distributed under the terms of Article $25 \mathrm{fa}$ of the Dutch Copyright Act, indicated by the "Taverne" license above, 


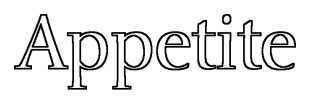

Appetite 45 (2005) 40-46

www.elsevier.com/locate/appet

Research Report

\title{
Food and the relation between values and attitude characteristics
}

\author{
Ellen Dreezens ${ }^{\mathrm{a}, *}$, Carolien Martijn ${ }^{\mathrm{a}}$, Petra Tenbült ${ }^{\mathrm{b}}$, Gerjo Kok ${ }^{\mathrm{a}}$, Nanne K. de Vries ${ }^{\mathrm{b}}$ \\ ${ }^{a}$ Department of Experimental Psychology, Maastricht University, P.O. Box 616, 6200 MD Maastricht, The Netherlands \\ ${ }^{\mathrm{b}}$ Department of Health Education and Health Promotion, Maastricht University, P.O. Box 616, 6200 MD Maastricht, The Netherlands
}

Received 1 October 2004; revised 1 December 2004; accepted 1 January 2005

\begin{abstract}
This survey showed that the values power (dominance over nature and resources) and universalism (respect for people and for nature) are related to attitudes toward genetically modified food (GMF) and organically grown food (OGF). Furthermore, these values have an influence on the centrality, commitment and ambivalence of these attitudes. Values that are positively related to an attitude influence how central this attitude is to a person. However, values that are negatively related to an attitude have a larger effect on the commitment of this attitude. No such pattern of effects was found for the relationship between ambivalence and values. These data suggest that centrality, commitment, and ambivalence are structurally different constructs that have a distinct relationship with specific values.
\end{abstract}

(C) 2005 Elsevier Ltd. All rights reserved.

Keywords: Attitudes; Values; Centrality; Commitment; Ambivalence; Genetic modification; Organic food

For some consumers, ideological considerations are important determinants of their food preferences. For example, for most vegetarians, their diet signifies an ideology of how life ought to be lived and not only what one is allowed to eat (Lindeman \& Sirelius, 2001). Although taste, price, availability and nutritional value are important factors, some people decide what, or what not to eat on the basis of moral considerations. Thus, in purchasing food, consumers' beliefs (e.g. organically grown food is good for the environment), attitudes (e.g. I am very positive toward organically grown food) and values (e.g. protection of all people and nature is important to me) are important determinants of their behavior. However, the main focus will be on the influence of values on food-related attitudes and attitude characteristics. Not only will we discuss the relationship between values and attitudes, but also more importantly, we will emphasize that values also have an effect on specific attitudinal characteristics like attitude strength and ambivalence. Therefore, the central question of this paper is: what are the structural relations between values and three attitudinal characteristics: centrality,

\footnotetext{
* Corresponding author.

E-mail address: e.dreezens@psychology.unimaas.nl (E. Dreezens).
}

0195-6663/\$ - see front matter @ 92005 Elsevier Ltd. All rights reserved. doi:10.1016/j.appet.2005.03.005 commitment and ambivalence. Values are important guidelines in people's lives. These three attitude characteristics not only give us information about the way an attitude is constructed, but also about how much the attitude is embedded into an underlying structure and how certain people are about their attitude. We will discuss this in the context of food-production technologies like genetic modification and organically grown food. These are two opposing attitude issues. Because previous research has already shown that these two attitude-issues differ in their attitude strength and ambivalence (Dreezens et al., unpublished data), they therefore provide a good means to study the influence of values on attitudes that differ in attitude characteristics.

\section{Attitudes}

An attitude is a psychological tendency that is expressed by evaluating a particular entity with some degree of favor or disfavor (Eagly \& Chaiken, 1995). An attitude is formed during the encounters a person has with an attitude-object. During these encounters, beliefs about the attitude object are formed. An attitude consists of an organization of several beliefs focused on a specific object or situation. Beliefs are defined as 'salient information relevant to the behavior' (Ajzen, 1991). An individual may hold several beliefs 
toward an object, and with each of these beliefs comes an evaluation. All these beliefs and their evaluations together form an attitude.

In this paper, we focused on two types of food products: genetically modified food (GMF) and organically grown food (OGF). The choice for these two types of products was made because of their assumed incompatibility. It seems likely that attitudes toward OGF and GMF are negatively related because GMF is manipulated and altered by human hands, whereas the OGF is characterized by 'naturalness' and 'pureness' (Schifferstein \& Oude Ophuis, 1998). Therefore, they represent an incompatibility in their underlying value structure. For some people, this incompatibility in underlying value structures is not a problem. They know very well what to think of the attitude-issue, because they for example only adhere to one of the values underlying these food-related attitudes. These people have a very strong attitude, which is not ambivalent. On the contrary, other people, who see both the advantages and disadvantages of an attitude-issue have a less strong and more ambivalent attitude. Therefore, these two attitudes provide us with a broader perspective of the influences that values can have on attitudes and attitude characteristics, than one attitude-issue would have.

\section{Values}

Values are assumed to be building blocks of attitudes (Eagly \& Chaiken, 1995; Verplanken \& Holland, 2002). Schwartz and Bilsky (1990) describe values as concepts or beliefs about desirable end states or behaviors, that transcend specific situations, guide the selection or evaluation of behavior, and are ordered by relative importance. Values are the most abstract of the social cognitions and serve as prototypes from which attitudes are derived (Homer \& Kahle, 1988; Luzar \& Cosse, 1998). Once a value is internalized, it becomes a standard or criterion for guiding action and for developing and maintaining attitudes toward relevant objects and situations. A persons' value system represents a learned organization of rules for making choices and for resolving conflicts (Rokeach, 1968, pp. 159-160). This means that, when people have to construct an attitude about new technologies like genetic modification, they may be guided by the values that they find important. If the attitude object fits with a person's values, he or she will probably derive a positive attitude toward the object.

A taxonomy of values that proved to be relatively stable among cultures was developed by Schwartz (1992). According to this taxonomy, there are ten motivational value types that can be found in every culture and each of the ten motivational values types is subdivided into more specific values. The ten high-level values are successively: self direction, stimulation, hedonism, achievement, power, security, conformity, tradition, benevolence and universalism (Schwartz, 1992). People in all cultures acknowledge these values and the only individual and cultural differences consist of which values are found most important and guide attitudes and behavior.

\section{Values and attitudes}

One of the prominent functions of attitudes is to express personal values (Katz, 1960), and therefore, attitudes have to be influenced by or related to the values that they express. Values affect attitudes by focusing not simply on the whole attitude, but by making some specific aspects of an attitude (beliefs) more salient or important. For example, imagine a person who holds the following beliefs about eating meat: 'eating meat is unethical' and 'meat tastes good'. If she considers the value universalism (protection for all people and for nature) as a guiding principle in her life, the first belief is probably more important and salient to her than the second belief. Because of the match between her value and a specific belief ('eating meat is unethical'), such a belief is likely to influence her overall attitude toward eating meat to a greater extent than beliefs that do not match her important values. This would mean that when dining in a restaurant, she will think twice before ordering a large steak. Vice versa, if another person considers hedonism (pleasure, enjoying life) as a guiding principle in life, the belief about excellent taste of meat will probably influence the attitude most. This person might then feel no guilt when eating a Big Mac for lunch.

Previous research, where the influence of the 10 values of the Schwartz Value Survey on the attitudes toward GMF an OGF was measured, showed that the attitude toward OGF was negatively related to the value power as well as positively related to the value universalism (Dreezens, Martijn, Tenbült, Kok, \& de Vries, 2005). However, GMF was positively related to the value power and negatively related to the value universalism. This survey showed that the two opposing attitude positions have a different connection with values. Participants who did not oppose human domination over the natural environment, or favored having everything under control, were also not opposed to influencing natural processes by making use of GMF. A high adherence to OGF, where human interventions are sparse and as natural as possible is not in line with the value power, but in line with the value universalism. Therefore, respondents who were in favor of OGF show a low adherence to the value power and a high adherence to universalism. It seemed that only the values power and universalism had an influence on the attitude toward GMF and OGF. Therefore, the focus in this paper will be on the relationship between these two values and the attitudes toward GMF and OGF. 


\section{Attitude strength}

Some attitudes are important to us, they are central to our being. Other attitudes are trivial and do not have a large effect on us. The attitudes that are important to us and that will often come to mind or lead us in our daily behavior are called strong attitudes. People's attitudes become stronger when they have more direct experience with an attitude object, when they are more involved with the attitude object, or when they have expressed their attitude frequently (Krosnick, Boninger, Chaung, Berent, \& Carnot, 1993; Lord, Lepper, \& Mackie, 1984). Strong attitudes are thought to have four characteristics (Pomerantz, Chaiken, \& Tordesillas, 1995). First, strong attitudes lead to selective cognitive processing. Second, strong attitudes are resistant to change. Third, strong attitudes are persistent over time and fourth, they are able to predict behavior. Because strong attitudes are important to a person, they easily spring to mind whenever the person encounters an attitude object. The behavior that follows from seeing this attitude object, is therefore, likely to be influenced by this particular attitude.

Additionally, there are two important strength dimensions: centrality and commitment (Holland, Verplanken, \& van Knippenberg, 2002). Centrality refers to the importance of an attitude to the self concept and personal values. Central attitudes are characterized by strong links between the attitude's core constituents (beliefs). Moreover, central attitudes are strongly embedded into the structure of personal values. Commitment refers to the certainty or conviction about the attitude. An attitude to which a person has a high commitment comes to mind very easily, and therefore, plays an important role in decision making. Because, there seems to be a difference in how much centrality and commitment are related to personal values, these two strength dimensions will be used to uncover the influence of values on attitude strength. We predict that values will have a different influence on centrality than on commitment.

\section{Ambivalence}

Another important aspect of attitudes that is related to attitude strength is whether or not the attitude is ambivalent. Ambivalence refers to a situation in which an individual has equally strong positive and negative evaluations toward an attitude object (Armitage \& Conner, 2000). In other words, people simultaneously see positive and negative sides of the attitude object, and this gives them an unresolved or unpleasant feeling. There is a negative relationship between attitude strength and ambivalence. Ambivalent attitudes are less guiding for behavior and less persistent over time, whereas strong attitudes are more guiding for behavior and persistent over time. However, since strength and ambivalence are theoretically different constructs, we wish to see if values have a differentiating role to play.

Ambivalence is associated with lower certainty of an attitude. Therefore, ambivalence might be mostly related to attitude commitment, and less to centrality. Since the centrality of an attitude is expected to be influenced by related values, it is not expected that ambivalence and values are highly related.

In the present paper, the data of six survey studies, all conducted between June 2002 and June 2004 were used. In every one of these studies, participants were asked about the values they adhered to, their attitudes toward GMF and OGF, their attitude strength and ambivalence toward these two attitude issues. Because all measures were the same in these 6 studies, it was possible to collapse these data into one sample, thereby improving generalizability and sample size. This overall sample consists of data of student- and consumer populations. Hereby we hoped that the data obtained in these analyses would shed a greater light on the issue than when only students would be considered.

\section{Method}

\section{Participants}

This overall sample consisted of 241 participants, both students (180) and consumers (61), of which 75 were men, with a mean age of 26.0 (ranging from 18 to 76 ).

\section{Measures}

In each of these six experiments, we asked people about their attitudes toward genetically modified food (GMF) and organically grown food (OGF) and about their attitude strength and ambivalence towards GMF and OGF. However, the centrality and commitment measures could only be computed for some of the participants, due to the fact that the answers on the individual attitude strength questions were not always available. Therefore, the total number of participants can vary between the different attitude characteristics.

(i) Values. Previous research (Dreezens et al., 2005) has shown that only the values power and universalism have an effect on the attitudes toward GMF and OGF. Therefore, we only used these two values. To do so, we used the power and universalism subscales of the Schwartz Value Survey (Schwartz, 1992). People were asked how important they found each of the sub values of the power and universalism subscales (like 'dominance' or 'respect') on a nine-point scale ranging from -1 (opposed to my values) to 7 (extremely important).

(ii) Attitudes. Four items were used to assess participant's attitudes toward GMF and the same four items measured attitudes toward OGF. Participants were 
asked to rate 'what do you in general think about GMF/OGF' on four 5-point scales varying from 1 (very unpleasant/very bad/very unfavorable/very negative) to 5 (very pleasant/very good/very favorable/very positive). An attitude index score was calculated for both GMF and OGF, using these four questions.

(iii) Centrality. A centrality index was composed by asking participants three questions. These were: 'how much do you personally care about GMF/OGF?' (very little-very much); 'how representative of your values is your attitude toward GMF/OGF?' (very unrepresentative-very representative); 'how central is your attitude toward GMF/OGF to your self-image?' (very peripheral-very central). Of these questions, a mean centrality score was calculated. These questions were measured on a 5-point scale.

(iv) Commitment. A commitment index was composed by asking participants four questions. These were: how certain are you that your opinion about GMF/OGF is correct?' (very uncertain-very certain); 'how often do you think about GMF/OGF?' (very little-very mисh); 'how interested are you in obtaining information about GMF/OGF?' (very uninterested-very interested) and 'how knowledgeable are you about GMF/OGF?' (very unknowledgeable-very knowledgeable). Of these questions, a mean commitment score was calculated. The questions for the centrality and commitment indexes were derived from several studies on attitude strength (Holland, Verplanken, and van Knippenberg, 2003; Lavine, Huff, Wagner, \& Sweeney, 1998; Pomerantz, Chaiken, \& Tordesillas, 1995). These questions were measured on a 5-point scale.

(v) Ambivalence. To assess ambivalence, three items were used. These were: 'I have doubts about my attitude toward GMF/OGF', 'I cannot choose between the pros and cons of GMF/OGF' and 'I have conflicting thoughts about GMF/OGF'. All ambivalence questions were answered on a five point scale with endpoints: not at all applicable - very much applicable. This ambivalence questionnaire was composed by using items that were taken from another study on attitude ambivalence (Jamieson, 1988).

\section{Results}

Attitudes

The overall attitude toward GMF in this sample was 2.98 on a scale from 1 to 5 , which means that people were relatively neutral about GMF. Furthermore, the overall attitude toward OGF was 4.15 on a scale from 1 to 5 , which means that people were positive toward OGF. These attitudes were significantly different from each other. This implies that students and consumers are in general more positive toward OGF than toward GMF. These results are summarized in Table 1.

\section{Attitudes and values}

To analyze how the values power and universalism were related to the attitudes towards GMF and OGF, two regression analyses were conducted. In the first analysis, both the values power and universalism added significantly to the prediction of the GMF attitude. However, power showed a positive contribution to the GMF attitude, $\beta=0.17, p<0.01$, whereas universalism showed a negative contribution to the GMF attitude, $\beta=-0.20, p<0.01$. In the second analysis, both power and universalism predicted the OGF attitude in a significant way. This time, universalism was positively related to the OGF attitude $\beta=0.21, p=0.001$, and power was negatively related to the OGF attitude, $\beta=-0.13, p<0.05$. These results show that the attitudes toward GMF and OGF relate differently to the values power and universalism. This is in accordance with previous research by Dreezens et al. (2005) that showed roughly the same pattern, only then for a population that consisted entirely of students. This is summarized in Table 2.

\section{Centrality, commitment and ambivalence}

Because a difference was expected in how values affected the three attitudinal characteristics, it seemed reasonable to first look at the correlations between these three concepts. Therefore, a correlational analysis was conducted in which centrality, commitment and

Table 1

Means, standard deviations and number of participants for the attitude, centrality, commitment and ambivalence of both GMF and OGF

\begin{tabular}{|c|c|c|c|c|c|c|c|}
\hline & \multicolumn{3}{|l|}{ GMF } & \multicolumn{3}{|l|}{ OGF } & \multirow[t]{2}{*}{$T$ (paired) } \\
\hline & $\mathrm{M}$ & SD & $\mathrm{N}$ & $\mathrm{M}$ & $\mathrm{SD}$ & $\mathrm{N}$ & \\
\hline Attitude & 2.98 & 0.98 & 237 & 4.15 & 0.88 & 240 & $13.76^{* *}$ \\
\hline Centrality & 2.31 & 0.68 & 173 & 2.96 & 0.94 & 175 & $8.49^{* *}$ \\
\hline Commitment & 2.25 & 0.78 & 175 & 2.73 & 0.84 & 175 & $6.62 * *$ \\
\hline Ambivalence & 2.87 & 0.90 & 241 & 2.53 & 0.80 & 241 & $5.02 * *$ \\
\hline
\end{tabular}

$* p<0.05 . * * p<0.01$. 
Table 2

The beta weights (and accompanying $p$-values) of the effect of the values power and universalism on the attitude, centrality, commitment and ambivalence of both GMF and OGF

\begin{tabular}{llllll}
\hline & \multicolumn{2}{l}{ GMF } & & & OGF \\
\cline { 2 - 3 } \cline { 5 - 6 } \cline { 5 - 6 } & Universalism $\beta$ & Power $\beta$ & & Universalism $\beta$ & Power $\beta$ \\
\hline Attitude & $-0.20^{* *}$ & $0.17^{* *}$ & & $0.21^{* * *}$ & $-0.13^{*}$ \\
Centrality & n.s. & $0.16^{*}$ & & $0.21^{* * *}$ & n.s. \\
Commitment & $0.17^{*}$ & n.s. & & n.s. & $-0.12^{*}$ \\
Ambivalence & n.s. & n.s. & & n.s. & $0.18^{* *}$ \\
\hline
\end{tabular}

$* p<0.05 ; * * p<0.01 ; * * * p<0.001$. The beta weights for centrality are corrected for the effect of commitment and vice versa.

ambivalence were used as variables. For GMF, there was a positive correlation between centrality and commitment ( $r=0.45, p<0.001)$. Furthermore, there was a negative correlation between ambivalence and commitment ( $r=-0.23, p<0.01$ ), but no correlation between ambivalence and centrality. For OGF, the same pattern occurred. There was a positive correlation between centrality and commitment $(r=0.67, p<0.001)$, a negative correlation between ambivalence and commitment $(r=-0.23, p<$ 0.01 ), but no correlation between ambivalence and centrality. Because of the high correlation between centrality and commitment, it was decided that when the relation between the values universalism and power on the one hand and either centrality or commitment on the other hand would be investigated, this relationship would be corrected for the influence of the other strength characteristic.

\section{Centrality, commitment and values}

Participants' attitudes toward GMF were both less central and less committed than their OGF counterparts (see also Table 1). When examining the relationship between power and universalism on the one hand and centrality and commitment of the attitudes toward GMF and OGF on the other hand, an interesting pattern occurred. A regression with the two values as predictor variables and centrality of the GMF attitude as dependent variable (but corrected for the effect of commitment, by adding commitment to the predictor variables) showed that only power could significantly predict the centrality of the attitude toward GMF, $\beta=0.16, p<0.05$. However, for commitment toward GMF (corrected for the effect of centrality), only the value universalism was a significant contributor, $\beta=0.17$, $p<0.05$.

A mirrored pattern was found for the centrality and commitment toward OGF. For centrality, universalism was a positive predictor of OGF, $\beta=0.21, p<0.001$. This relationship between centrality and universalism was corrected for the effect of commitment. Furthermore the value power was negatively connected to the commitment toward OGF (corrected for centrality) $\beta=-0.12, p<0.05$. This is summarized in Table 2.

\section{Ambivalence and values}

The overall data showed that people were significantly more ambivalent toward GMF than toward OGF (see also Table 1). Two regression analyses with power and universalism as predictors and the ambivalence of the attitudes toward GMF and OGF as dependent variables showed that the ambivalence of these two attitude issues was not very strongly related to values. For ambivalence toward GMF, neither power nor universalism had an effect on the ambivalence scores. However, for ambivalence toward OGF, only the value power had a significant positive effect, $\beta=0.18, p<0.01$. This is summarized in Table 2 .

\section{Discussion}

The purpose of this survey was to investigate whether values have an influence on attitudes as well as on centrality, commitment and ambivalence. Traditionally, the role of values has been researched in the light of their relationship to attitude issues, but to a lesser extent in their relationship to specific attitude characteristics. Because the attitudes toward GMF and OGF differ in their attitude strength and ambivalence, these two attitude issues were chosen to illustrate the ideas discussed in this paper.

It was confirmed that the attitudes toward GMF and OGF indeed differed on several attitude characteristics. First of all, the attitude toward OGF was more positive than the attitude toward GMF. This was probably due to the fact that GMF is considered to be a scary development by many people and is associated with negative affect (Laros \& Steenkamp, in press). Second of all, the attitude toward OGF was more central and more committed than the attitude toward GMF. Participants held their OGF attitude with more confidence and this attitude was more embedded into its internal structure than the attitude toward GMF. Third of all, the attitude toward OGF was less ambivalent than the attitude toward GMF. Participants experienced more conflict regarding their attitude toward GMF than regarding their attitude toward OGF.

Furthermore, it was shown that the two attitude issues have a different relationship with the values power and universalism. Power had a positive effect on the attitude toward GMF and a negative effect on the attitude toward OGF. For universalism, this pattern was reversed. These results replicate the results of a previous survey (Dreezens et al., 2005). This implies that, although the same values underlie the two attitude issues, the underlying pattern is not the same, and it is this pattern that determines a persons' attitude.

Another interesting finding was that ambivalence, centrality and commitment seem to be different constructs (although the correlation between centrality and commitment was relatively high). Theoretically, there has been much debate about whether all attitude strength characteristics (like ambivalence, centrality and commitment) could 
be summarized into one variable or that these characteristics are different constructs. Our results imply that, although there is some overlapping between these three constructs, they are structurally different. For example, ambivalence was only slightly related to values, whereas both centrality and commitment were more related to values. Therefore, these three constructs each cover a part of the attitude strength construct that the other two do not.

Values have a different effect on centrality than on commitment. The results suggest that the values that have a positive effect on the attitude toward GMF and OGF are the ones influencing the level of centrality (how much is your attitude related to its underlying values). For GMF, people who adhered to power, had a more central attitude than people who did not adhere to power. The value universalism (which is negatively related to the attitude toward GMF) had no effect on centrality. However, for the attitude toward OGF, the value universalism had an effect on the centrality of the attitude (whereas the value power had none effect whatsoever). Thus, the stronger the positive relationship between an attitude and a value, the more central the attitude (influenced by that particular value) will be. For commitment (the certainty or conviction about the attitude), exactly the opposite pattern occurred. It seemed that the values that are related to the attitude in a negative way, influence the level of commitment the most. For example, the attitude toward OGF becomes more committed as people are more opposed to the value power.

However, there was one exception to this pattern. The commitment of the attitude toward GMF was indeed related to the value universalism, but not in a negative way as was expected on the basis of the relationship between universalism and the attitude toward GMF. Why this was the case is not entirely clear. Perhaps the ambivalence of the attitude toward GMF had a role to play in this finding. Ambivalence means that people have conflicting thoughts about an attitude issue. This means that they could consider both power and universalism important values, and therefore, were not able to make up their minds about GMF. This way, universalism could have had both a negative influence on the attitude toward GMF, and a positive influence on the commitment of the attitude toward GMF.

The pattern of results, where centrality is related to values that have a positive influence on related attitudes and commitment is related to values that have a negative influence on related attitudes is somewhat surprising. However, it is probably due to the fact that centrality is, more than commitment, related to the self concept. This means that in defining yourself, the attitudes and values most central to you will probably play a large role. However, people define themselves and the things that are important to them in a positive manner. A person holding a positive attitude toward OGF will probably see him or herself as 'adhering to the value universalism' and not as 'not adhering to the value power'. We, therefore, assume that centrality is related to the values that have a positive influence on the attitude issue at hand. For commitment, which is not highly related to the self concept, this effect (describing yourself in positive terms) has a much smaller influence. However, more generally, other research has noted a tendency for negative information to result in larger cognitive, emotional, and social responses (Ito, Larsen, Smith, \& Cacioppo, 1998; Taylor, 1991). This might mean that (when people are not motivated to use positive information like when dealing with the self) negative information gives a person more assurance and influences attitudes to a larger extent. It is therefore, not surprising that values that have a negative influence on attitudes play a larger role in the commitment of an attitude.

Another issue to be considered is the fact that, although a relationship exists between attitudes, attitude characteristics and values, this is a significant but weak one. However, we did not expect to find large relationships between these concepts. Ajzen \& Fishbein (1977) state that attitudes and behavior must be correspondent in their level of specificity to make sure that a strong relation between the two can be found. They claim that a very specific attitude is much more able to predict a very specific behavior than a more general attitude. We expected that the same principle also holds for the relationship between attitudes and values. Values are more abstract concepts than attitudes, and this makes it difficult for the concepts to influence each other. This however means, that finding any relationships between the two, is more meaningful than when the relationship could be easily found.

All in all, this survey showed that the values power and universalism are related to the centrality, commitment and ambivalence of the attitudes toward GMF and OGF. Centrality, commitment, and ambivalence are structurally different constructs that have a distinct relationship with values. Therefore, we cannot simply say that strong attitudes are more related to values than weak attitudes, but attitude strength needs to be unraveled into these three components to see their autonomous influences. This way, the complicated relationships between food-related attitudes, attitude characteristics and values become more insightful and easier to interpret.

\section{Acknowledgements}

This research was supported by a grant from ZonMw (01412-001). The authors would like to thank Alard Roebroeck for his helpful comments on earlier drafts of this paper.

\section{References}

Ajzen, I. (1991). The theory of planned behavior. Organizational Behavior and Human Decision Processes, 50, 179-211.

Ajzen, I., \& Fishbein, M. (1977). Attitude-behavior relations: A theoretical analysis and review of empirical research. Psychological Bulletin, 84, 888-918. 
Armitage, C., \& Conner, M. (2000). Attitudinal ambivalence: A test of three key hypotheses. Personality and Social Psychology Bulletin, 26, 1421-1432.

Dreezens, E., Martijn, C., Tenbült, P., Kok, G., \& de Vries, N. K. (2005). Food and values: An examination of values underlying attitudes toward genetically modified-and organically grown food products. Appetite, 44, 115-122.

Eagly, A. H., \& Chaiken, S. (1995). Attitude strength, attitude structure and resistance to change. In R. E. Petty, \& J. A. Krosnick, Attitude strength: Antecedents and consequences. Ohio State University series on attitudes and persuasion (Vol. 4). Hillsdag, NJ, USA: Lawrence Erlbaum Associates, Inc..

Holland, R. W., Verplanken, B., \& van Knippenberg, A. (2003). From reprtition to conviction: attitude accessibility as a determinant of attitude certainty. Journal of Experimental Social Psychology, 39, 594-601.

Homer, P. M., \& Kahle, L. R. (1988). A structural equation test of the value-attitude-behavior hierarchy. Journal of Personality and Social Psychology, 54, 638-646.

Ito, T. A., Larsen, J. T., Smith, N. K., \& Cacioppo, J. T. (1998). Negative information weighs more heavily on the brain: The negativity bias in evaluative categorizations. Journal of Personality and Social Psychology, 75, 887-900.

Jamieson, D.W. (1988). The influence of value conflicts on attitudinal ambivalence. Paper presented at the annual meeting of the Canadian Psychological Association, Montreal.

Katz, D. (1960). The functional approach to the study of attitudes. PublicOpinion-Quarterly, 24, 163-204.

Krosnick, J. A., Boninger, D. S., Chaung, Y. C., Berent, M. K., \& Carnot, C. G. (1993). Attitude strength: One construct or many related constructs? Journal of Personality and Social Psychology, 65, 1132-1151.

Laros, F. J. M., \& Steenkamp, J.-B. E. M. (in press). Emotions in consumer behavior: A hierarchical approach. Journal of Business Research.
Lavine, H., Huff, J. W., Wagner, S. H., \& Sweeney, D. (1998). The moderating influence of attitude strength on the susceptibility to context effects in attitude surveys. Journal of Personality and Social Psychology, 75, 359-373.

Lindeman, M., \& Sirelius, M. (2001). Food choice ideologies: The modern manifestations of normative and humanist views of the world. Appetite, $37,175-184$.

Lord, C. G., Lepper, M. R., \& Mackie, D. (1984). Attitude prototypes as determinants of attitude-behavior consistency. Journal of Personality and Social Psychology, 46, 1254-1266.

Luzar, E. J., \& Cosse, K. J. (1998). Willingness to pay or intention to pay: The attitude-behavior relationship in contingent valuation. Journal of Socio-Economics, 27, 427-444.

Pomerantz, E. M., Chaiken, S., \& Tordesillas, R. S. (1995). Attitude strength and resistance processes. Journal of Personality and Social Psychology, 69, 408-419.

Rokeach, M. (1968). A theory of organization and change: Beliefs, attitudes and values. San Francisco, USA: Jossey-Bass, Inc., Publisher.

Schifferstein, H. N. J., \& Oude Ophuis, P. A. M. (1998). Health-related determinants of organic food consumption in The Netherlands. Food Quality and Preference, 9, 119-133.

Schwartz, S. H. (1992). Universals in the content and structure of values: Theoretical advances and empirical tests in 20 countries. In M. P. Zanna, Advances in experimental social psychology (Vol. 25) (pp. 1-65). Waterloo: Academic Press, Inc.

Schwartz, S. H., \& Bilsky, W. (1990). Toward a theory of the universal content and structure of values: Extensions and cross-cultural replications. Journal of Personality and Social Psychology, 58, 878-891.

Taylor, S. E. (1991). Asymmetrical effects of positive and negative events: The mobilization-minimization hypothesis. Psychological Bulletin, 110, 67-85.

Verplanken, B., \& Holland, R. W. (2002). Motivated decision making: Effects of activation and self-centrality of values on choices and behavior. Journal of Personality and Social Psychology, 82, 434-447. 